Eixo Temático: Educação Não-Formal

\title{
ET-08-001 \\ MÉTODO FÁCIL E SEGURO PARA DESTINAÇÃo DE PILHAS, BATERIAS E VIDROS QUEBRADOS
}

Marilia Carolina Pereira da Paz¹, Suelen Cláudia Barbosa Lopes¹, Ronilson José da Paz

${ }^{1}$ Discente. Curso de Licenciatura Plena em Ciências Biológicas. Universidade Federal da Paraíba. Centro de Ciências Exatas e da Natureza. João Pessoa-PB. (CEP 58051-900).

${ }^{3}$ Docente. Escola de Ensino Fundamental Gonçalves Dias. Analista Ambiental do IBAMA-PB. Caixa Postal 5063. João Pessoa-PB. (CEP 58051-900). E-mail: ronilson.paz@gmail.com.

http://dx.doi.org/10.21472/congrebio2016.et-08-001

\section{RESUMO}

Tendo em vista que a legislação ambiental não permite a disposição final de baterias de chumbo-ácido nos aterros sanitários, tampouco a sua incineração, esses materiais devem ser recolhidos e entregues diretamente ao serviço de limpeza urbana do município, que deverá destinar corretamente esses resíduos sólidos. Além disso, vidros quebrados podem provocar acidentes com os agende de limpeza urbana, devendo ter tramento especial pela população. Neste trabalho é apresentado um método fácil e seguro para a correta e adequada destinação de baterias, vidros e lâmpadas quebradas, de modo a não degradar o meio ambiente, tampouco causar acidentes com os profissionais que lidam com esse tipo de resíduos. Confeccionado com a reutilização de garrafas PET, o método é extremamente simples e não oneroso, permitindo a correta destinação desses resíduos sólidos, visando à proteção da saúde pública e da qualidade ambiental.

Palavras-chaves: Resíduos sólidos; Gestão de resíduos especiais; Lojística reversa;

\section{INTRODUÇÃO}

Tendo em vista que a legislação ambiental não permite a disposição final de baterias de chumbo-ácido nos aterros sanitários, tampouco a sua incineração, as pilhas e baterias devem ser recolhidas e entregues diretamente à Autarquia Especial de Limpeza Urbana (EMLUR), que deverá destinar corretamente esses resíduos sólidos.

A correta destinação dos resíduos sólidos, visando à proteção da saúde pública e da qualidade ambiental, é o principal instrumento para a manutenção de um meio ambiente saudável e sustentável (BRUM e SILVEIRA, 2011; KEMERICH et al., 2011).

O controle da destinação correta das pilhas e baterias que contenham em suas composições chumbo, cádmio, mercúrio em seus compostos, foi imposto pela Resolução CONAMA nº 257/1999 (BRASIL, 1999):

Art. $1^{\circ}$ As pilhas e baterias que contenham em suas composições chumbo, cádmio, mercúrio e seus compostos, necessárias ao funcionamento de quaisquer tipos de aparelhos, veículos ou sistemas, móveis ou fixos, bem como os produtos eletro-eletrônicos que as contenham integradas em sua estrutura de forma não substituível, após seu esgotamento energético, serão entregues pelos usuários aos estabelecimentos que as comercializam ou à rede de assistência técnica autorizada pelas respectivas indústrias, para repasse aos fabricantes ou importadores, para que estes adotem, diretamente ou por meio de terceiros, os procedimentos de reutilização, reciclagem, tratamento ou disposição final ambientalmente adequada. 
As pilhas e baterias enquadram-se, quanto a sua natureza e origem, em resíduos domiciliares especiais, classificadas pela ABNT NBR 10004:2004 (ABNT, 2004):

Classe I ou perigosos - são aqueles que, em função de suas características intrínsecas de inflamabilidade, corrosividade, reatividade, toxicidade ou patogenicidade, apresentam riscos à saúde pública por meio do aumento da mortalidade ou da morbidade, ou ainda provocam efeitos adversos ao meio ambiente quando manuseados ou dispostos de forma inadequada. (ABNT, 2004).

A Lei $\mathrm{n}^{\circ}$ 12.305/2010 impõe que a destinação final dos resíduos sólidos devem ser ambientalmente adequada, devendo incluir a reutilização, a reciclagem, a compostagem, a recuperação e o aproveitamento energético ou outras destinações admitidas pelos órgãos competentes do Sistema Nacional de Meio Ambiente (SISNAMA), do Sistema Nacional de Vigilância Sanitária (SNVS) e do Sistema Unificado de Atenção à Sanidade Agropecuária (SUASA), entre elas a disposição final, observando normas operacionais específicas de modo a evitar danos ou riscos à saúde pública e à segurança e a minimizar os impactos ambientais adversos (BRASIL, 2010).

Esta lei estimula a reutilização dos resíduos sólidos de modo que os materiais tenham longevidade maior, contribuindo para a diminuição dos resíduos que são destinados aos aterros sanitários.

Este trabalho tem como objetivo, apresentar um método para a correta e adequada destinação de baterias, vidros e lâmpadas quebradas, de modo a não degradar o meio ambiente, tampouco causar acidentes com os profissionais que lidam com esse tipo de resíduos.

\section{METODOLOGIA}

Para a confecção de um recipiente para condicionamento de pilhas e baterias foram usados fita adesiva, estilete, cordão e garrafa PET com capacidade de um litro (Figura 1).

Fez-se um corte na garrafa PET com tamanho suficiente e necessário para que pudessem passar a maioria dos tipos de pilhas e baterias existentes no mercado (Figura 2).

Para acondicionamento de vidros quebrados e lâmpadas queimadas e quebradas, cortouse a garrafa PET com capacidade para um litro em dois pedaços, próximo a sua garganta, sendo um maior que o outro, colocou-se os cacos de vidro e lâmpadas queimadas ou quebradas dentro da garrafa e com o auxílio fita adesiva juntou-se os pedaços da garrafa, vendando-a (Figura 3).

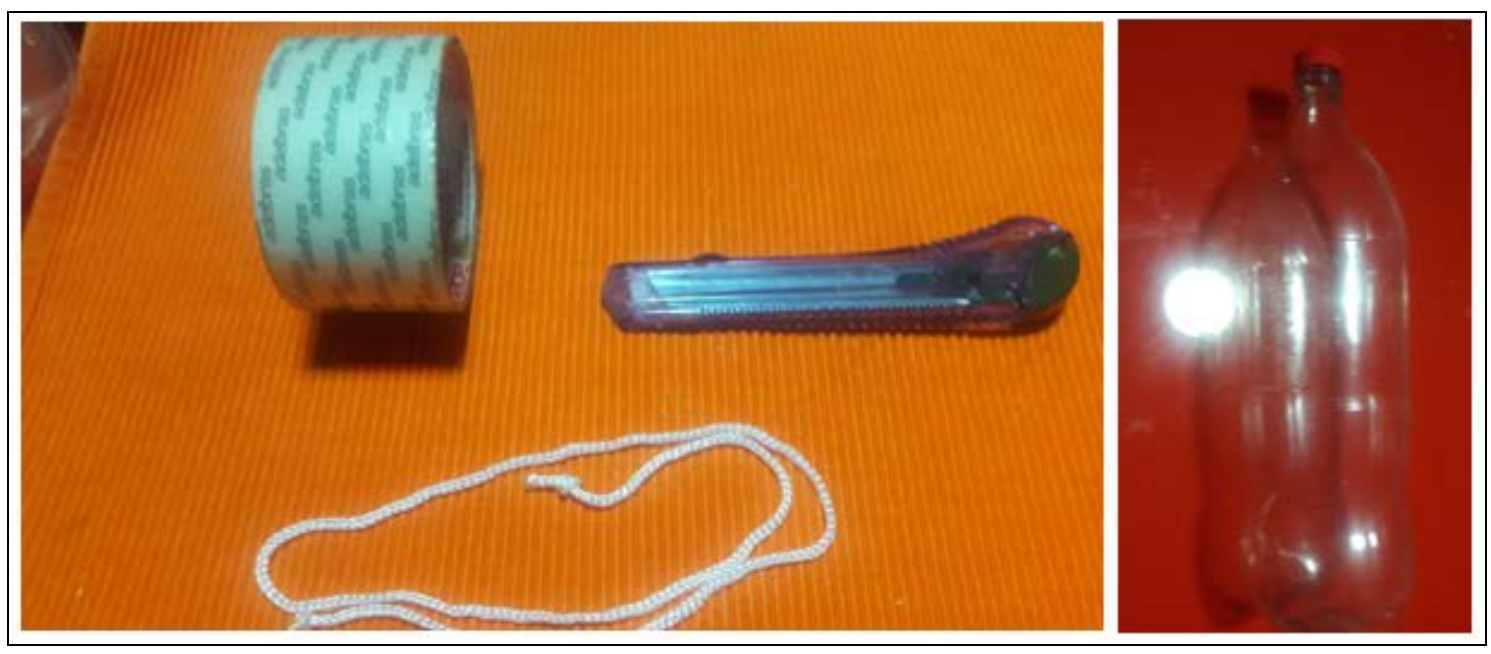

Figura 1. Materiais utilizados. Fita adesiva, estilete, cordão e garrafa PET. 


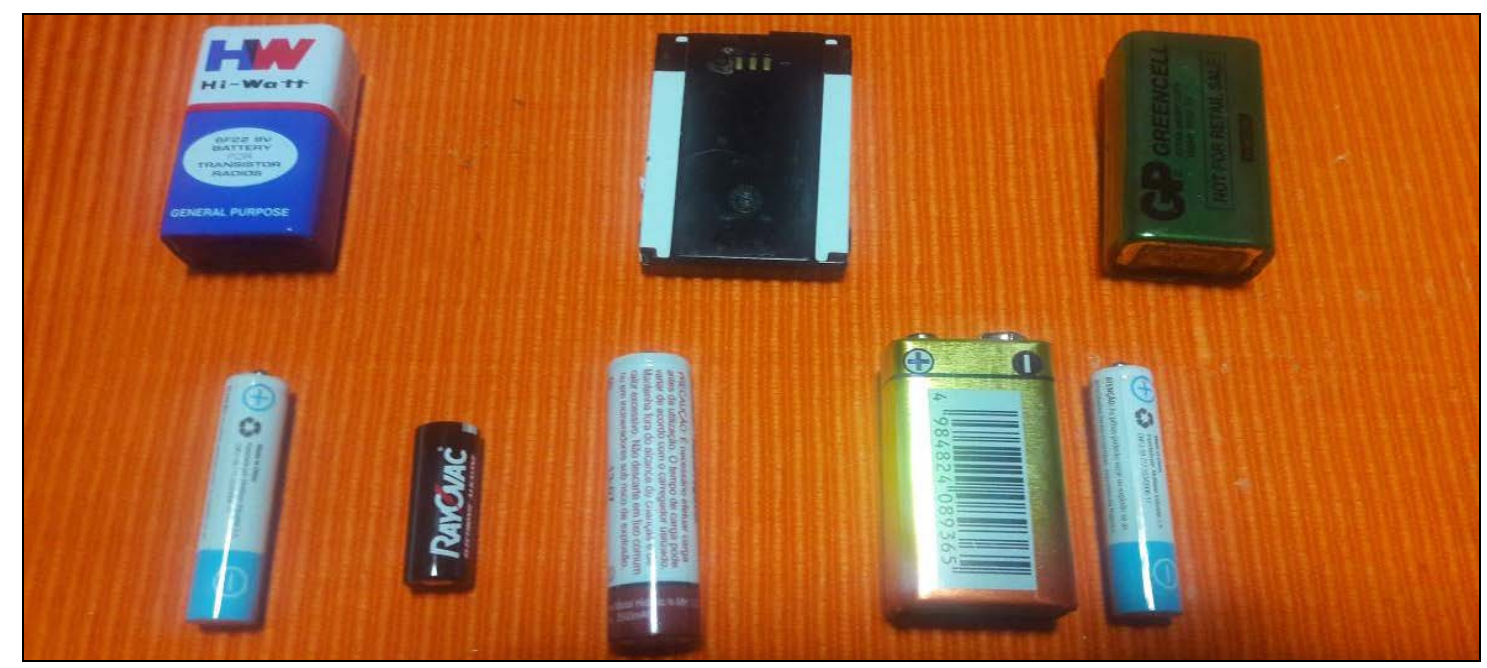

Figura 2. Devido à flexibilidade da garrafa PET, vários tipos de pilhas e baterias podem ser depositados no recipiente.

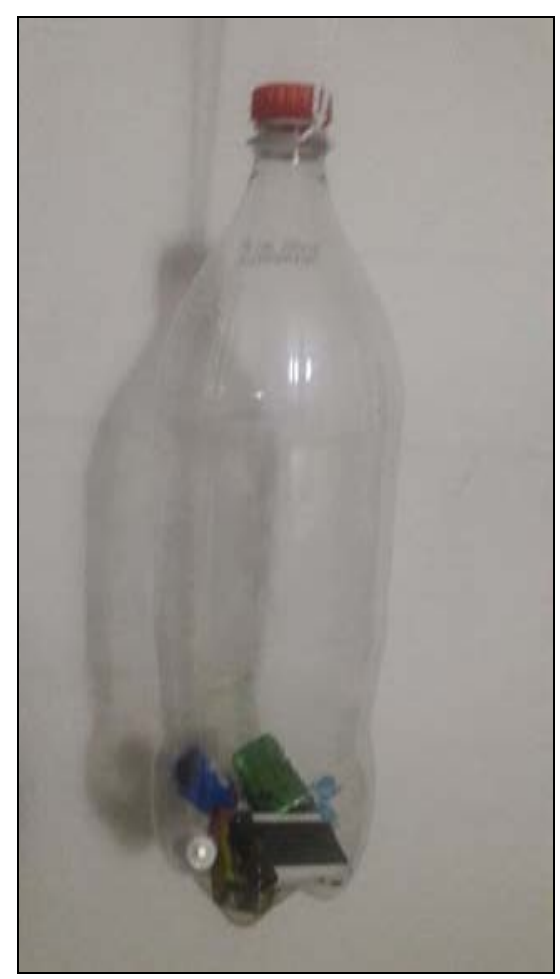

Figura 3. Recipiente pronto para receber as pilhas e baterias.

\section{CONSIDERAÇÕES FINAIS}

A utilização da garrafa PET para a confecção do recipiente para a coleta de pilhas, baterias, vidros quebrados e lâmpadas quebradas e queimadas mostrou-se bastante promissora, 
tendo em vista que a flexibilidade do material PET permite o depósito de uma gama de baterias que são vendidas no mercado.

Com o auxílio de um cordão, o recipiente poderá ficar exposto e receber as pilhas, baterias, vidros quebrados e lâmpadas quebradas e queimadas de uma sala de aula, de uma secretaria, de um escritório e, após o seu preenchimento, ser entregue ao serviço de coleta de resíduos sólidos do município, que poderá dar a destinação desses materiais, diminuindo ou evitando a contaminação do meio ambiente (BOCCHI et al., 2000) e dos profissionais que trabalham recolhendo os resíduos.

O descarte errado de cacos de vidro tem causado sérios acidentes nos profissionais que recolhem os resíduos sólidos (PINHO e NEVES, 2010). Embora em João Pessoa não haja uma estimativa com relação a esses acidentes, mas há a suspeita de que agulhas, vidros e lâmpadas queimadas e quebradas são responsáveis por vários acidentes.

Desse modo, a utilização de um recipiente confeccionado com garrafa PET reutilizada (Figura 4), para acondicionar cacos de vidros, lâmpadas quebradas e queimadas, bem como outros tipos de materiais perfuro-cortantes, como agulhas, poderá evitar os acidentes nos garis.
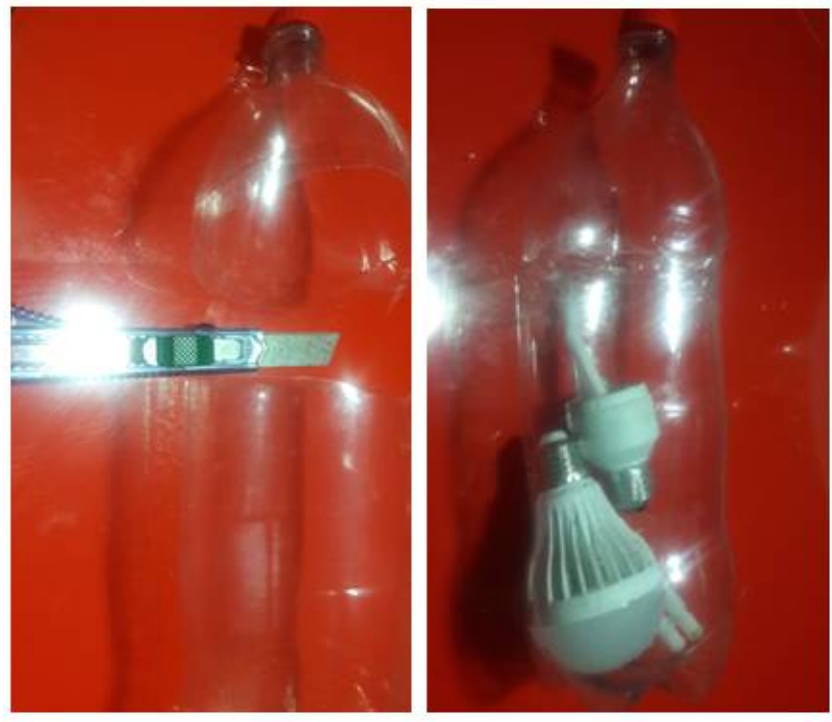

Figura 4. Recipiente de garrafa PET para o acondicionamento de cacos de vidros, lâmpadas quebradas e queimadas, bem como outros tipos de materiais perfuro-cortantes (agulhas, por exemplo).

\section{CONCLUSÃO}

Com a apresentação dessa metodologia para a correta destinação de pilhas, baterias, cacos de vidros e lâmpadas quebradas e queimadas, observa-se que com poucos recursos e muita criatividade pode-se contribuir para se chegar a um meio ambiente equilibrado e sem riscos de contaminações que possam influir negativamente na saúde dos profissionais responsáveis pelo recolhimento dos resíduos sólidos.

\section{REFERÊNCIAS}

ABNT - ASSOCIAÇÃO BRASILEIRA DE NORMAS TÉCNICAS. ABNT NBR 10004:2004. Resíduos sólidos - Classificação. Rio de Janeiro: ABNT, 2004. 
BRASIL. Leis, decretos, etc. Lei $\mathbf{n}^{\mathbf{0}}$ 12.305, de 2 de agosto de 2010. Institui a Política Nacional de Resíduos Sólidos; altera a Lei $\mathrm{n}^{\circ}$ 9.605, de 12 de fevereiro de 1998; e dá outras providências. Disponível em: <http://www.planalto.gov.br/ccivil_03/_ato2007-2010/2010/lei/112305.htm>. Acesso: 14 fev. 2016.

BRASIL. Leis, decretos, etc. Resolução CONAMA no 257, de 30 de junho de 1999. Disponível em: <http://www.mma.gov.br/port/conama/res/res99/res25799.html>. Acesso: 14 fev. 2016.

BOCCHI, N.; FERRACIN, L. C.; BIAGGIO, S. R. Pilhas e baterias: funcionamento e impacto ambiental. Química Nova na Escola, n. 11, p. 3-9, 2000. Disponível em: $<$ http://www.qnesc.sbq.org.br/online/qnesc11/v11a01.pdf>. Acesso: 14 fev. 2016.

BRUM, Z. R.; SILVEIRA, D. D. Educação Ambiental no uso e descarte de pilhas e baterias. Revista Eletrônica em Gestão, Educação e Tecnologia Ambiental, v. 2, n. 2, p. 205-213, 2011.

KEMERICH, P. D. C.; MENDES, S. A.; VORPAGEL, T. H.; PIOVESAN, M. Descarte indevido de pilhas e baterias: a percepção do problema no Município de Frederico Westphalen RS. Revista Eletrônica em Gestão, Educação e Tecnologia Ambiental, v. 8, n. 8, p. 16801688, 2012. http://dx.doi.org/10.5902/223611706319

PINHO, L. M.; NEVES, E. B. Acidentes de trabalho em uma empresa de coleta de lixo urbano. Cad. Saúde Colet., Rio de Janeiro, v. 18, n. 2, p. 243-251, 2010. Disponível em: $<$ http://www.cadernos.iesc.ufrj.br/cadernos/images/csc/2010_2/artigos/CSCv18n2_243251.pdf $>$. Acesso em: 14 maio 2016. 